\title{
Intelligent Risk Prediction of Storage Tank Leakage Using an Ishikawa Diagram with Probability and Impact Analysis
}

\author{
Favour Ikwan ${ }^{1}$, David Sanders ${ }^{1}$, Malik Haddad ${ }^{1}$, Mohamed Hassan $^{2}$, \\ Peter Omoarebun ${ }^{1}$, Mohamad Thabet ${ }^{3}$, Giles Tewkesbury ${ }^{1}$, Branislav Vuksanovic ${ }^{3}$ \\ ${ }^{1}$ School of Mechanical \& Design Engineering, University of Portsmouth, Portsmouth, UK. \\ ${ }^{2}$ School of Chemical Engineering, University of Southampton, Southampton, SO17 1BJ, UK \\ ${ }^{3}$ School of Energy and Electronic Engineering, University of Portsmouth, Portsmouth, UK. \\ Favour.Ikwan@myport.ac.uk
}

\begin{abstract}
Intelligent probability and impact analysis are used with an Ishikawa diagram. Causes of tank leakage events are identified. Causes were ranked and weights assigned to show their relative importance in the diagram. A Risk Score for each category of causes is identified using probability and impact analysis. The application is explored to predict the risk of leakage in a storage tank. That risk can be mixed with real time data to create an intelligent system. Various methods can be used to predict future system states centred upon an analysis of trends within historic or past data. A simple human computer interface is presented to display the results by overlaying 'Fail' or 'Warning' states on a schematic of a storage tank. Important information can be flagged alongside conditions. As an example, a surface graph, representing the storage tank condition over a ten-week period is displayed. A continuing deterioration in the score connected with "lack of operating procedures" is presented.
\end{abstract}

Keywords: Ishikawa, Petroleum, Risk Analysis, Storage Tank.

\section{Introduction}

This paper describes the application of an Ishikawa diagram to predict the leakage risk within a storage tank by ranking and assigning weights to causes to show their relative importance.

Probability and impact analysis were used to calculate a Risk-Score for individual categories of causes. The application was further explored to predict the risk of leakage in a storage tank. That risk could be mixed with real time data to create an intelligent system.

Fires in tanks containing crude oil and explosions are recurrent accidents within oil terminals, petroleum refineries and petroleum storage facilities. They often result in human casualty, environmental pollution, and economic loss [1]. In order to minimize these accidents, risks needed to be minimized and controlled. Attention to the safety of industrial plants has increased and accidental release within petroleum processing facilities [2]. Risk could be defined as the possibility that someone or something is badly affected by a hazard and danger as a result of an unsafe situation or because of a potential damaging or undesirable event [3]. Risk could also be defined as a measure of hazard severity, or a measure of the probability and the severity of damage.

A simple human computer interface is presented to display the results. An Ishikawa diagram (also called a "cause and effect" [4] or "Fishbone" diagram) was named after "Kaoru Ishikawa", who originally developed the diagram in the 1960's [5]. It could be used as a tool to identify root cause(s) for specific problems. It also afforded an organized way of considering causes and effects that created or contributed to top level effects. The diagram aided in identifying possible causes for a problem that might not otherwise be considered by focusing on the categories and considering alternative causes. In addition, the schema would be utilized to ascertain risks of sub-cause risk, cause risk and global-risk [6].

A model receiving continuous data would be processed with human and environmental factors. It would then be converted into real time risk. Such a real-time depiction of risk (current and cumulative) could help in making intelligent decisions using critical information and insight.

There were numerous methods to show information in a complete, inclusive and user-friendly way. Specifically, "design for usability" and "human factors" were reviewed [7] and a main dashboard was represented using an Excel® spreadsheet.

\section{Construction of an Ishikawa Diagram}

The Ishikawa diagram was created according to the logic scheme in Fig. 1. 


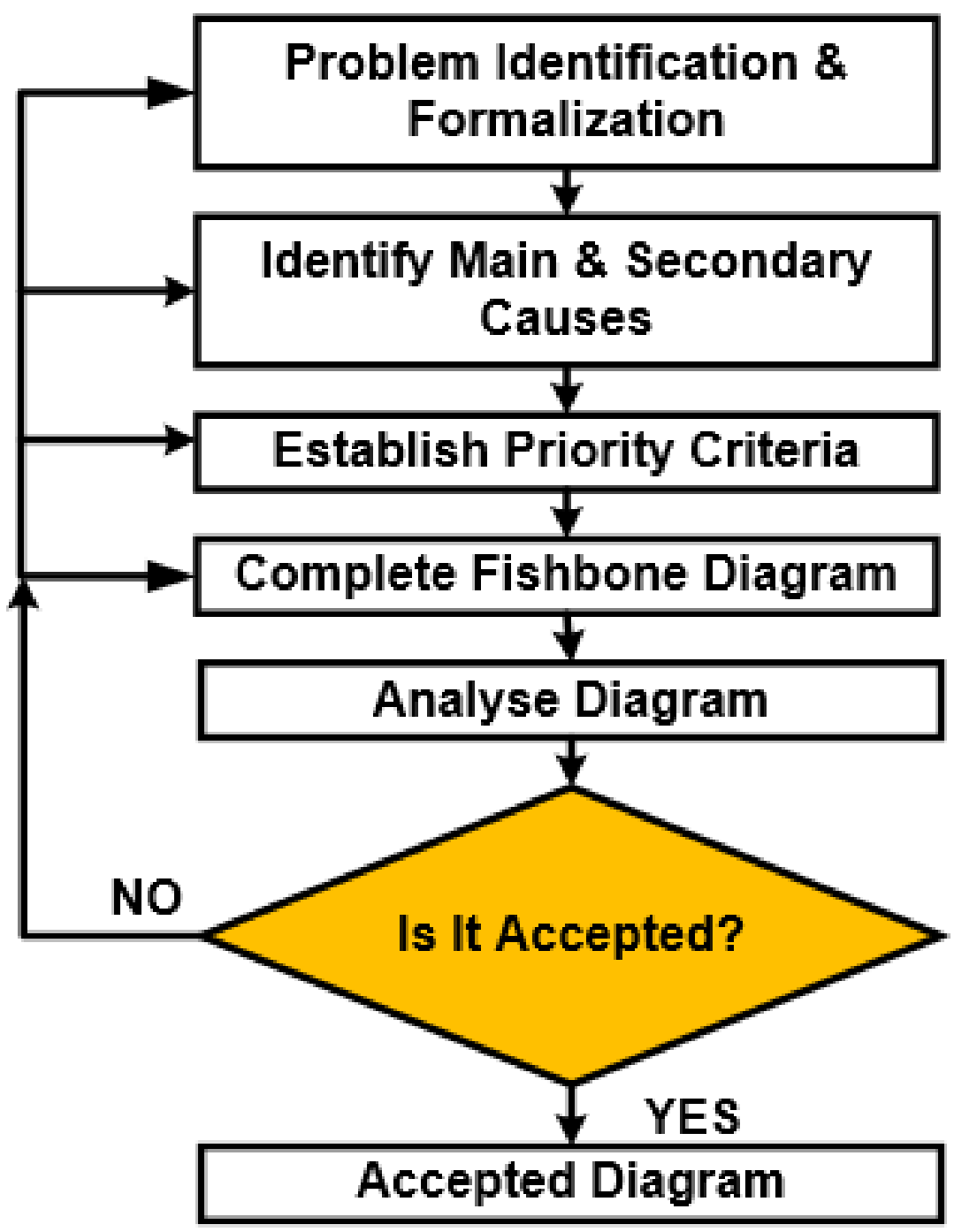

Fig. 1. A Logic Scheme for implementation.

Problems, accidents, risks or consequences were identified and analyzed. The secondary and main-causes of the problem were established.

The diagram was created and assessed against the following conditions [8]:

- "Impact" (I) and "Probability of occurrences" (P) were derived and depicted by an equation $\mathrm{R}=\mathrm{P} * \mathrm{I}$.

- Causes were depicted by possibility, frequency of occurrence or probability.

- Main-causes were regarded as effects (of second order or secondary).

- There was an objective with an operational motive.

- Causes of secondary effects were illustrated by named side-effects, and perpetrated identical conditions to maincauses.

- The same conditions as for problem identification were fulfilled to identify main and secondary-causes.

Repartition of causes and sub-causes could be in a preference order or could be random. Risk was analyzed after accepting the diagram. A course of action for risk causes was established along with global-risk for the effect (characterized event).

\section{Analysis of "Leak in a Storage Tank" Diagram}

Accidents could also result in stock devaluation, lawsuits or company bankruptcy [9]. Risk is an uncertain condition or event that has a negative or positive effect on one or more objectives. The problem "leakage in a storage tank" was an undesirable event which could lead to a negative effect.

The risk allotted to the event was called "risk of leakage in a storage tank". The risk illustrated the dynamic using probability distribution of the effect occurring and the impact of the effect. Risk was expressed on a scale from 0 to 3 or an integer $(1,2,3)$. A simplified Ishikawa diagram is shown in Fig. 2. The Ishikawa diagram was reduced for the ease of explanation in this paper. Some main and secondary-causes were deleted to simplify the diagram. 


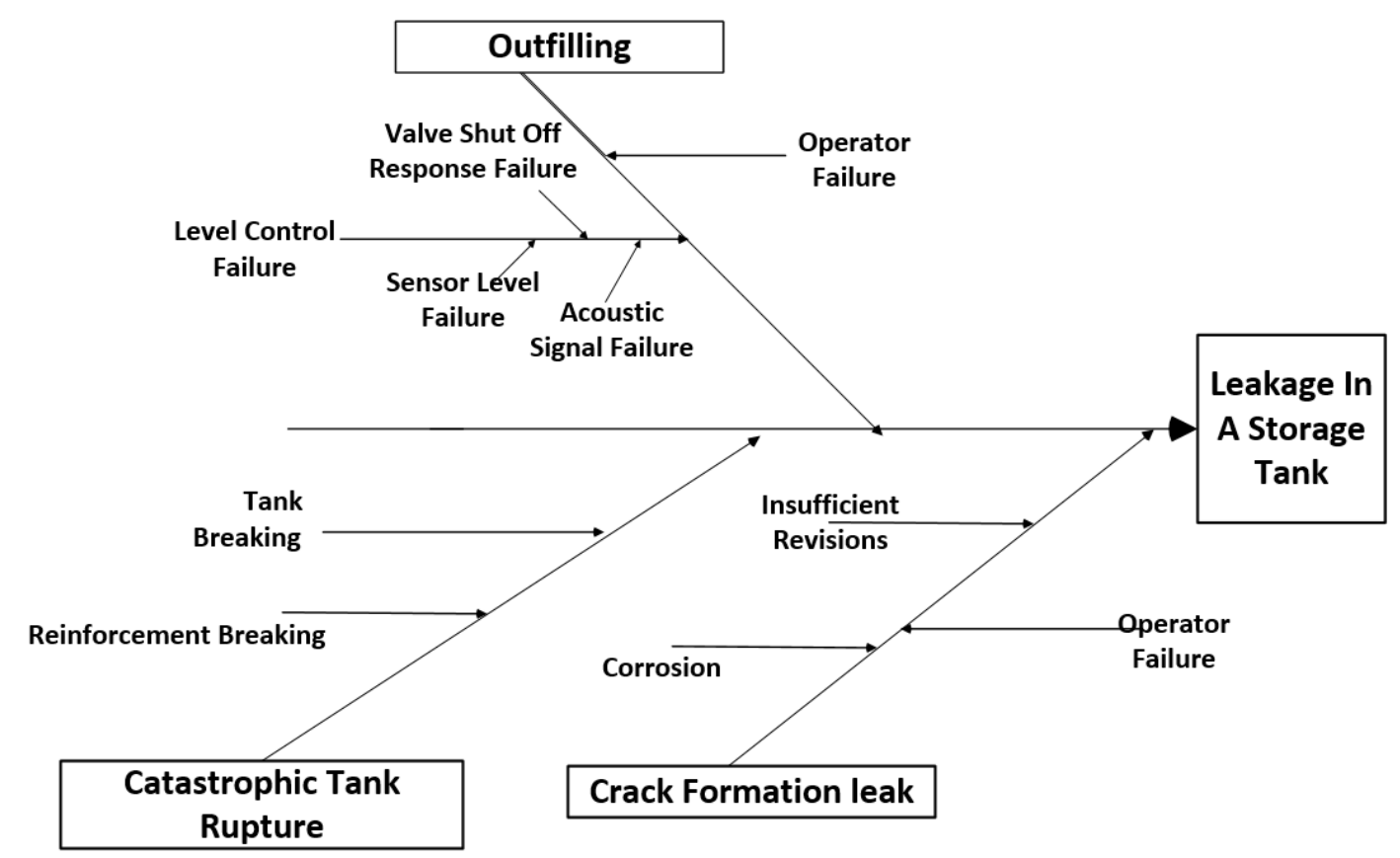

Fig. 2. A simplified Ishikawa diagram for the risk of leakage in a storage tank.

Fig. 2 is characterized by three main-causes (outfilling, catastrophic tank rupture and crack formation leak) and nine secondary-causes. The representation on the diagram axis had the main-causes situated above and to the left of the axis (outfilling), and below and to the right of the axis (catastrophic tank rupture and crack formation leak). Main and secondarycauses represent main-causes relevant to the process. Secondary-causes were selected to be nigh to the portrayal of the risk.

\section{Codification of Causes}

Cause codification was crucial during risk analysis when making use of an Ishikawa diagram as it allowed for a simpler depiction of causes and operation [10]. Codification was formulated on:

- belonging to the right or left of the diagram;

- internal (endogenous) or external (exogenous) cause distribution;

- frequency of occurrence;

- $\quad$ grouping of code to be more representative;

- option to convert codification if criteria change;

Table 1 shows a simplified codification of the causes shown in Fig. 2.

Table 1. Codification of causes and sub-causes.

\begin{tabular}{|l|l|l|l|}
\hline Issue & Cause & Subcause & Code \\
\hline 1 & Outfilling & & $\mathrm{A}_{1}$ \\
\hline 1.1 & & Operator Failure & $\mathrm{A}_{11}$ \\
\hline 1.2 & & Valve Shut Off Response & $\mathrm{A}_{12}$ \\
\hline 1.3 & & Sensor Level Failure & $\mathrm{A}_{13}$ \\
\hline 1.4 & & Acoustic Signal Failure & $\mathrm{A}_{14}$ \\
\hline 2 & Catastrophic Tank Rupture & & $\mathrm{Z}_{1}$ \\
\hline 2.1 & & Tank Breaking & $\mathrm{Z}_{11}$ \\
\hline 2.2 & & Reinforcement Breaking & $\mathrm{Z}_{12}$ \\
\hline 3 & Crack Formation Leak & & $\mathrm{Z}_{2}$ \\
\hline 3.1 & & Corrosion & $\mathrm{Z}_{21}$ \\
\hline 3.2 & & Insufficient Revisions & $\mathrm{Z}_{22}$ \\
\hline 3.3 & & Operator Failure & $\mathrm{Z}_{23}$ \\
\hline
\end{tabular}




\section{Determining Risk of Leakage in a Storage Tank}

A leakage in a storage tank was the global-risk $(\mathrm{Rg})$ in this model. Global-risk was shaped by risk of yielding a main-cause and exemplifies a weighted-sum representing a main-cause. Leakage in a storage tank, $\mathrm{Rg}$, depicted the weighted-sum of risks from categories shown above and to the left $(\mathrm{Ra})$, and below and to the right of the axis (Rz).

$$
\mathrm{Rg}=\mathrm{Pa} * \mathrm{Ra}+\mathrm{Pz} * \mathrm{Rz}
$$

Where the total of left and right category weights should equal one.

$$
(\mathrm{Pa}+\mathrm{Pz}=1)
$$

Each risk category was a weighted-sum of main risk causes allocated to right or left.

$$
R a=\sum_{i=1}^{n} P_{i} * R a_{i} ; \sum_{i=1}^{n} P_{i}=1
$$

$\boldsymbol{R} \boldsymbol{a}_{i}$ were the main-causes allocated to the left of diagram axis and $\boldsymbol{R} \boldsymbol{z}_{j}$ were the main-causes allocated to the right axis.

$$
R z=\sum_{j=1}^{n} P_{j} * R z_{j} ; \sum_{j=1}^{n} P_{j}=1
$$

Each main-cause risk illustrated the weighted-sum of secondary-cause risks to give.

$$
R a_{i}=\sum_{i, k} P_{i k} * R a_{i k} ; \sum_{i, k} P_{i k}=1
$$

Where $\boldsymbol{R} \boldsymbol{a}_{\boldsymbol{i}}$ represented the secondary-cause risks, which established main-causes on the left:

$$
R z_{j}=\sum_{j, l} P_{j l} * R z_{j l} ; \sum_{j, l} P_{j l}=1
$$

Where $\boldsymbol{R}_{\boldsymbol{z}_{j l}}$ described the secondary-cause risks, which established the main-causes on the right.

Global-risk was determined from direct formalizations or extracted from tables based on:

- $\quad$ Secondary-cause risks were determined ( $\boldsymbol{R} \boldsymbol{a}_{\boldsymbol{i} \boldsymbol{k}}$ and $\boldsymbol{P}_{\boldsymbol{i} \boldsymbol{k}} ; \boldsymbol{R} \boldsymbol{z}_{\boldsymbol{j} \boldsymbol{l}}$ and $\boldsymbol{P}_{\boldsymbol{j} \boldsymbol{l})}$ );

- Main-cause risks were determined from weighted-sums of secondary-causes risks and evaluated using $\boldsymbol{R} \boldsymbol{a}_{i}$ and $\boldsymbol{P}_{\boldsymbol{i}}$

\begin{tabular}{|c|c|c|c|c|c|c|}
\hline & \multicolumn{2}{|l|}{ Code } & \multirow{2}{*}{$\begin{array}{l}\text { Weights of } \\
\text { Sec Causes }\end{array}$} & \multirow{2}{*}{$\begin{array}{l}\text { Weight } \\
\text { Control }\end{array}$} & \multirow{2}{*}{$\begin{array}{l}\text { Weight of } \\
\text { Main Causes }\end{array}$} & \multirow{2}{*}{$\begin{array}{l}\text { Weight } \\
\text { Control }\end{array}$} \\
\hline & Main & Sec. & & & & \\
\hline $\begin{array}{l}1 \\
1.1 \\
1.2 \\
1.3 \\
1.4\end{array}$ & $\mathrm{~A}_{1}$ & $\begin{array}{l}\mathrm{A}_{11} \\
\mathrm{~A}_{12} \\
\mathrm{~A}_{13} \\
\mathrm{~A}_{14}\end{array}$ & $\begin{array}{l}0.4 \\
0.3 \\
0.2 \\
0.1\end{array}$ & 1 & 1 & 1 \\
\hline $\begin{array}{l}2 \\
2.1 \\
2.2 \\
\end{array}$ & $\mathrm{Z}_{1}$ & $\begin{array}{l}Z_{11} \\
Z_{12}\end{array}$ & $\begin{array}{l}0.55 \\
0.45\end{array}$ & 1 & 0.5 & 1 \\
\hline $\begin{array}{l}3 \\
3.1 \\
3.2 \\
3.3 \\
\end{array}$ & $\mathrm{Z}_{2}$ & $\begin{array}{l}Z_{21} \\
Z_{22} \\
Z_{23} \\
\end{array}$ & $\begin{array}{l}0.44 \\
0.38 \\
0.18 \\
\end{array}$ & 1 & 0.5 & \\
\hline
\end{tabular}
and $\boldsymbol{R}_{\boldsymbol{j}}$ and $\boldsymbol{P}_{j}$;

- $\quad$ Risk categories ( $\boldsymbol{R} \boldsymbol{a}$ and $\boldsymbol{R} \boldsymbol{z})$ were determined and evaluated for global-risk ( $\boldsymbol{P a}$ and $\boldsymbol{P} \boldsymbol{z})$;

- Global-risk $(\boldsymbol{R g})$ was determined.

Weights were determined and weights assessment were depicted in a weights table as shown in Tables 2 and 3.

Table 2. Main and secondary weights.

Table 3. The matrix of secondary and main cause weights and categories.

\begin{tabular}{|c|c|c|c|c|c|}
\hline \multirow{2}{*}{ Secondary Causes } & \multicolumn{3}{|c|}{ Main Causes } & \multirow{2}{*}{$\begin{array}{c}\text { Weight } \\
\text { Control }\end{array}$} & $\begin{array}{c}\text { Effect } \\
\text { Weight }\end{array}$ \\
\cline { 2 - 4 } & $\mathrm{A}_{1}$ & $\mathrm{Z}_{1}$ & $\mathrm{Z}_{2}$ & & \\
\hline $\mathrm{A}_{11}$ & 0.4 & & & & \\
$\mathrm{~A}_{12}$ & 0.3 & & & \\
$\mathrm{~A}_{13}$ & 0.2 & & & \\
$\mathrm{~A}_{14}$ & 0.1 & & & \\
\hline Weight Control & 1 & & & \\
\cline { 1 - 2 } $\mathrm{Z}_{11}$ & & 0.55 & & & \\
$\mathrm{Z}_{12}$ & & 0.45 & & & \\
\hline
\end{tabular}




\begin{tabular}{|c|c|c|c|c|c|}
\hline Weight Control & & 1 & & & \\
\hline $\mathrm{Z}_{21}$ & & & 0.44 & & \\
\hline $\mathrm{Z}_{22}$ & & & 0.38 & & \\
\hline $\mathrm{Z}_{23}$ & & & 0.18 & & \\
\hline Weight Control & & & 1 & & \\
\hline Left Category A & 1 & & & 1 & 0.44 \\
\hline Right Category Z & & 0.5 & 0.5 & 1 & 0.56 \\
\hline Weight Control & & & & & 1 \\
\hline
\end{tabular}

Settlement of causes in the matrix of weights illustrated a different way of presenting weights, benefitting from a disclosure about any direct relationships between secondary and main-causes.

In order to determine the global-risk (the risk of leakage in a storage tank), the following algorithms were determined:

- $\quad$ risks of secondary-causes $\left(\mathrm{Ra}_{\mathrm{ik}}\right.$ and $\left.\mathrm{Rz}_{\mathrm{jl}}\right)$;

- $\quad$ risks of main-causes $\left(\mathrm{Ra}_{\mathrm{i}}\right.$ and $\left.\mathrm{Rz} \mathrm{z}_{\mathrm{j}}\right)$;

- $\quad$ risks categories by secondary-causes ( $\mathrm{Ra}$ and $\mathrm{Rz})$;

- $\quad$ global-risk $(\mathrm{Rg})$.

The following calculations were conducted to apply an Ishikawa diagram in the case of "risk of leakage in a storage tank":

Risks of secondary-causes: These were determined using $R=P^{*} I$, so that risk R equalled probability of event occurrence (P) multiplied by consequences or impact of it occurring (I). Impact and probabilities of the occurrence of this event were calculated using methods described in [6] and [10] and were listed in Table 4.

Table 4. Impact, probability and risk evaluated for causes.

\begin{tabular}{|l|l|l|l|l|}
\hline Current Issue & Cause & Probability & Impact & Risk \\
\hline 1 & $\mathrm{~A}_{11}$ & 0.75 & 0.35 & 0.26 \\
2 & $\mathrm{~A}_{12}$ & 0.75 & 0.28 & 0.21 \\
3 & $\mathrm{~A}_{13}$ & 0.75 & 0.46 & 0.34 \\
4 & $\mathrm{~A}_{14}$ & 0.75 & 0.15 & 0.11 \\
\hline 5 & $\mathrm{Z}_{11}$ & 0.43 & 1 & 0.43 \\
6 & $\mathrm{Z}_{12}$ & 0.43 & 0.82 & 0.35 \\
\hline 7 & $\mathrm{Z}_{21}$ & 0.55 & 0.72 & 0.39 \\
8 & $\mathrm{Z}_{22}$ & 0.55 & 0.44 & 0.24 \\
9 & $\mathrm{Z}_{23}$ & 0.55 & 0.56 & 0.30 \\
\hline
\end{tabular}

Considering the frequency of occurrence of the secondary-causes, probabilities could be similar for different categories or groups of causes or for an entire group of causes but the impact was not likely to be the same [10]. For simplicity, equal probabilities were evaluated for secondary-causes and a main-cause was determined. Impact was evaluated in a different way for every secondary-cause.

Determining risk for main-causes: This was based on relationships between secondary-cause risks and their weights in determining a main-cause as shown in Table 3 and 4.

$\mathbf{R a}_{1}=\mathrm{Pa}_{11} * \mathrm{Ra}_{11}+\mathrm{Pa}_{12} * \mathrm{Ra}_{12}+\mathrm{Pa}_{13} * \mathrm{Ra}_{13}+\mathrm{Pa}_{14} * \mathrm{Ra}_{14}$

$\mathbf{R z} 1=\mathrm{Pz}_{11} * \mathrm{Rz}_{11}+\mathrm{Pz}_{12} * \mathrm{Rz}_{12}$.

$\mathbf{R z}=\mathrm{Pz}_{21} * \mathrm{Rz}_{22}+\mathrm{Pz}_{23} * \mathrm{Rz}_{14}+\mathrm{Pz}_{15} * \mathrm{Rz}_{15}$

Therefore,

$\mathbf{R a}_{1}=(0.4 * 0.26)+(0.3 * 0.21)+(0.2 * 0.34)+(0.1 * 0.11)$

$=0.10+0.063+0.068+0.011=0.242$.

$\mathbf{R z}_{1}=(0.55 * 0.43)+(0.45 * 0.35)=0.236+0.157=0.393$.

$\mathbf{R z}_{2}=(0.44 * 0.39)+(0.38 * 0.24)+(0.18 * 0.30)=(0.171+0.091+0.054)=0.316$.

Determining secondary-cause categories: This was based on the definition of the weighted-sum of the risks of secondarycauses for a particular category:

$\mathbf{R a}=\mathbf{p}_{1} * \mathbf{R a} 1$.

$\mathbf{R a}=1 * 0.242=0.242$.

$\mathbf{R z}=\mathbf{p}_{\mathbf{1}} * \mathbf{R} \mathbf{z}_{1}+\mathbf{p}_{\mathbf{2}} * \mathbf{R} \mathbf{z}_{1}$.

$\mathbf{R z}=(0.5 * 0.393)+(0.5 * 0.316)=(0.196+0.158)=0.354$

Determining global-risk: This was based on a definition of risk weighted-sums of cause categories: $\mathbf{R g}=(0.44 * 0.242)+(0.56 * 0.324)=(0.106+0.18)=0.287$.

\section{$6 \quad$ Interpretation of Results}

On a scale of risk with three intensities (SLIGHT, MODERATE, IMPORTANT), a rate of 0.287 for global-risk of "leak in storage tank" positioned it as risk "MODERATE" (1.18 on a scale of 0 to 3). Risks and main-cause categories can frame the event represented by risk as shown in Table 5. 
Table 5. Vulnerabilities table.

\begin{tabular}{|l|l|l|l|l|}
\hline Issue & Cause & Code & Risk value & Risk area \\
\hline 1 & Outfilling & $\mathrm{A}_{1}$ & 0.242 & Minor \\
\hline 2 & Catastrophic Tank Rupture & $\mathrm{Z}_{1}$ & $0.393(1.62)$ & Major \\
\hline 3 & Crack Formation Leak & $\mathrm{Z}_{2}$ & $0.316(1.30)$ & Medium \\
\hline 4 & Left Category & $\mathrm{A}$ & $0.242(1)$ & Minor \\
\hline 5 & Right Category & $\mathrm{Z}$ & $0.324(1.33)$ & Medium \\
\hline
\end{tabular}

Risk treatment measures were considered. The vulnerability of the organization to this threat (leak in a storage tank) was determined. The left category had SLIGHT vulnerability for the causes and the right category had MODERATE vulnerability for the causes. The vulnerability of the organization with regards to the secondary-causes were:

SLIGHT for Outfilling.

IMPORTANT for Catastrophic Tank Rupture.

MODERATE for Crack Formation leak.

Other methods could have been used to interpret risk values. For example, comparing values calculated with a fixed acceptable level [10] or assuming that the acceptance level (Rp) for "risk of leakage in a storage tank" was 0.20 (SLIGHT $0.82)$, and the value of global-risk $(0.287 ; 1.18$ - MODERATE) was compared.

If:

$\mathrm{Rg}<\mathrm{Rp}$, then risk is ignored,

$\mathrm{Rg}>\mathrm{Rp}$, then risk must be promptly improved.

Considering the example reflected in this paper,

$\mathrm{Rg}=0.287(1.18)>\mathrm{Rp}=0.2(0.82)$.

Therefore, treatment measures were required. Necessity of measures are shown in Table 6 .

Table 6. Necessity of measures.

\begin{tabular}{|l|l|l|l|l|}
\hline Issue & Cause & Code & Situation & Necessity of Measures \\
\hline 1 & Outfilling & $\mathrm{A}_{1}$ & $0.242>0.2$ & Yes \\
\hline 2 & Catastrophic Tank Rupture & $\mathrm{Z}_{1}$ & $0.393>0.2$ & Yes \\
\hline 3 & Crack Formation Leak & $\mathrm{Z}_{2}$ & $0.316>0.2$ & Yes \\
\hline 4 & Left Category & $\mathrm{A}$ & $0.242>0.2$ & Yes \\
\hline 5 & Right Category & $\mathrm{Z}$ & $0.324>0.2$ & Yes \\
\hline
\end{tabular}

\section{$7 \quad$ Hierarchy of Causes}

A model of hierarchy could be created by weighting towards the value of the main-cause to present the cause contribution to the organizations' vulnerability [8]. Hierarchy of causes for the case of risk is shown in Table 7.

Table 7. Table showing the hierarchy of causes.

\begin{tabular}{|l|l|l|l|l|}
\hline Issue & Cause & Code & Size & Hierarchy \\
\hline 1 & Catastrophic Tank Rupture & $\mathrm{Z}_{1}$ & 0.393 & 1 \\
\hline 2 & Crack Formation leak & $\mathrm{Z}_{2}$ & 0.316 & 2 \\
\hline 3 & Outfilling & $\mathrm{A}_{1}$ & 0.242 & 3 \\
\hline
\end{tabular}

Weights of causes were established. The biggest value was 0.393 in the case analyzed. Weights for other causes were determined by multiplying weighting value (Mp) by the normalized risk value. Weighted values of secondary-cause risks are in Table 8.

Table 8. Table of Weighted values

\begin{tabular}{|l|l|l|l|l|}
\hline Issue & Cause & Code & Size & Weighted Value \\
\hline 1 & Catastrophic Tank Rupture & $\mathrm{Z}_{1}$ & 0.393 & 10 \\
\hline 2 & Crack Formation leak & $\mathrm{Z}_{2}$ & 0.316 & 8.04 \\
\hline 3 & Outfilling & $\mathrm{A}_{1}$ & 0.242 & 6.15 \\
\hline
\end{tabular}




\section{Real Time Data}

A model receiving continuous data, could be processed with human and environmental factors and translated into real time insight and risk awareness. Representing current and cumulative risk in real time could help in making decisions by providing some critical insight and information.

Dynamic Risk Modelling combines the effect of technical conditions and human decisions and allows real-time data to be made available and linked with decisions and risk awareness, and could also provide an insight into the effect of hazards when controls or barriers fail or change.

Predictive tools could be used with a variety of methods to predict future states of systems based on an analysis of historic trends. From these trends, a next expected value could be determined.

\section{Human Computer Interface}

Fixed roof tanks as shown in Fig. 3 are employed to store various refined products, including heavy fuel oils and volatile material. A spreadsheet was used to present the main dashboard as it suited the requirement in order to see the objective. However, this was not the most systematic way of presenting information.

Efficiency was attained by over-laying "Fail" or "Warning" situations onto a representation of a storage tank with pertinent information highlighted alongside the fail or warning situations.

\section{Mesh \\ (Bird arrestor Open vent or flame arrestor)}

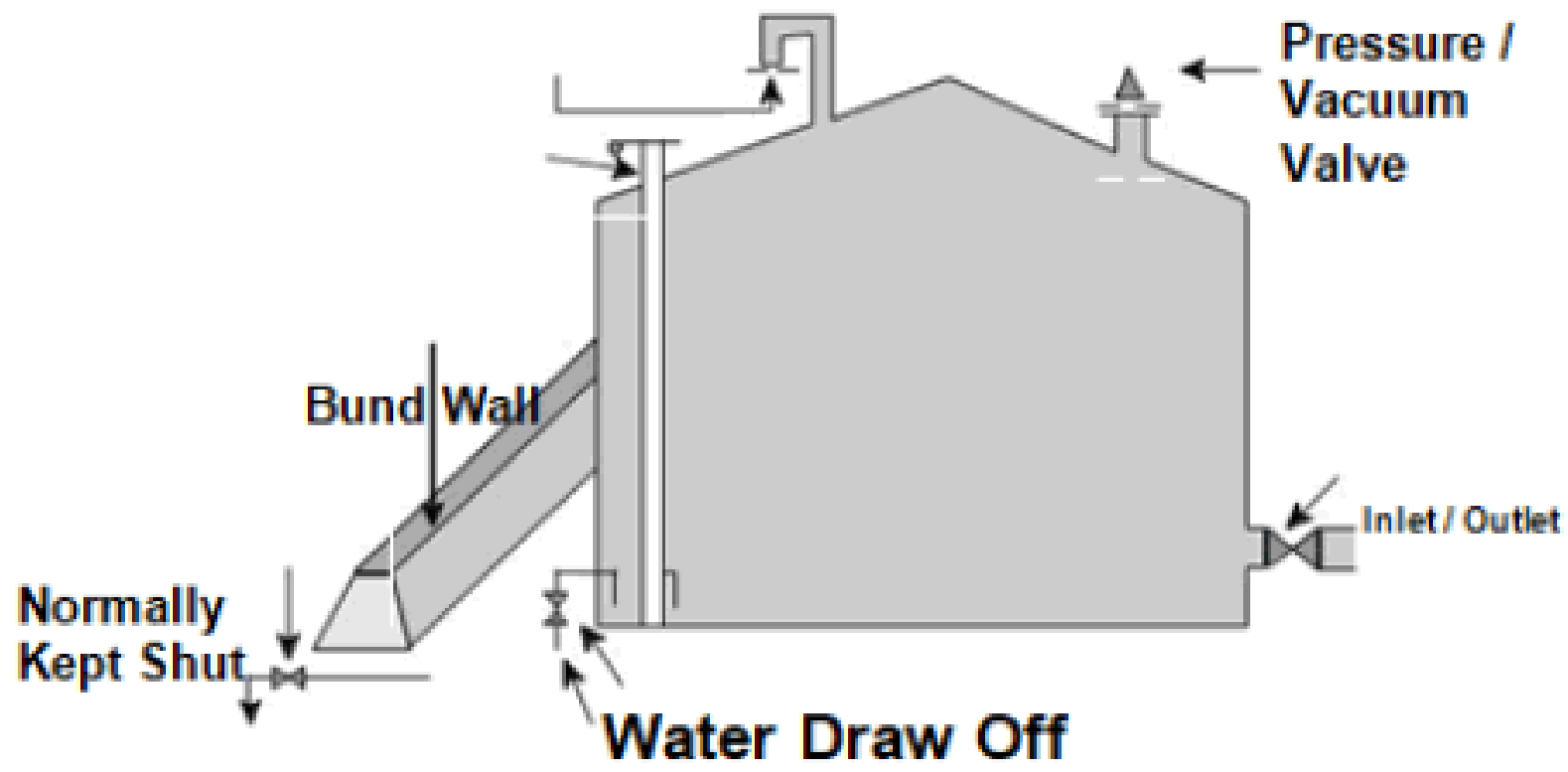

Fig. 3. Fixed roof tank.

As an example, the surface graph, representing the storage tank condition over ten days (see Fig. 4), shows a steady reduction in the score associated with 'lack of operating procedures". Ten traits were scored between ' 0 ' and ' 9 ' against a set of criteria to deliver a regular and consistent approach to capture and nominate trait conditions. The assignment of Green, Amber and Red color: Good = Green (7-9), Warning = Amber (4-6), and Fail = Red (0-3).

The pattern showing the 'States' (shown in Fig. 4 at the top of the surface-graph towards week 4), illustrated a change in 'State' (that is a change in color) when the level of the trait fell to 3. An operator observing a steady decline in a trait level(s) could reasonably predict that the level could continue dropping until a dangerous level is reached. 


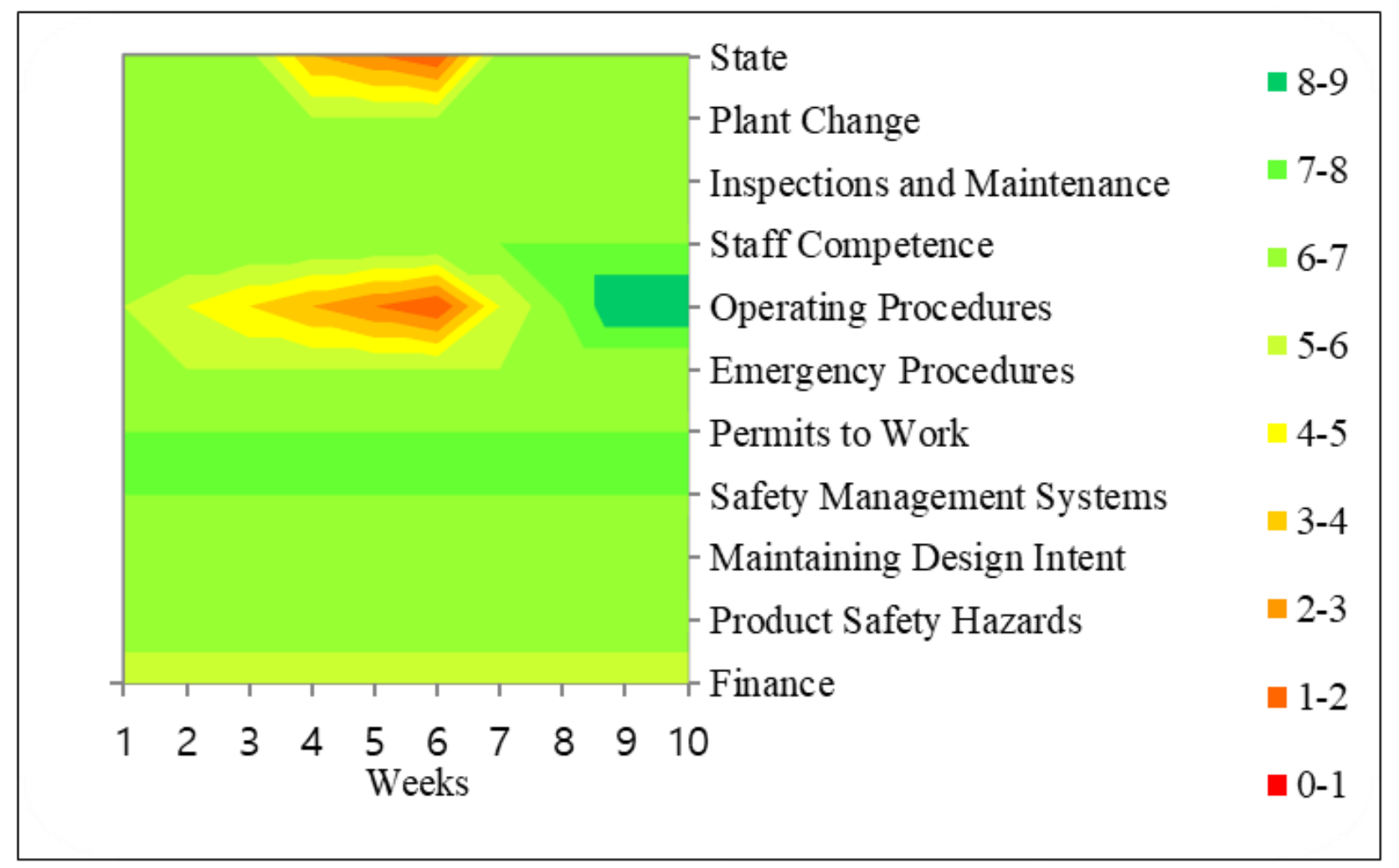

Fig. 4. Storage tank ten (10) days surface plot.

It could not be guaranteed that humans might be able recognize a dire situation and intervene. Instead, an intelligent system might recognize a reducing level(s) and draw attention to the likelihood of further reduction until dangerous levels might be reached.

This ability to predict relies on an analysis of trends within the real time data. That is, future data could be predicted by projecting forward using trend analysis to predict future states depending on historic states. The Excel ${ }^{\circledR}$ linear regression function could provide a straightforward way of predicting future states for traits, based on current real time data.

\section{Discussion and Conclusion}

An example of risk evaluation was presented for storage facilities because leakage of crude oil from a storage tank might lead to catastrophic accidents. Risks and consequences were identified and an Ishikawa diagram was created. Main and secondary-causes were finalized.

The problem "leakage in a storage tank" was an undesirable event. Risk assigned to the event represented not only the dynamic state depending on probability of an effect occurring but also on the potential impact of an event. Risk was expressed on a scale of three levels. Codification of causes was completed because it was important in risk analysis and allowed an easier operation and representation of the causes. Leakage in a storage tank was the global-risk. It was conditioned by the risk of producing main-causes and represented the weighted-sum of the main-causes.

The risk of main and secondary-causes, causes categories and global-risk were determined. This allowed structuring of treatment measures for vulnerable areas. The method involved evaluation of the impact of the causes, weights and probabilities, and helped in understanding the essence of risk analysis, risk treatment measures and risk values.

On a scale of risk having three levels (SLIGHT, MODERATE, IMPORTANT), the vulnerability with regards to the secondary-causes were SLIGHT for outfilling, IMPORTANT for catastrophic tank rupture and MODERATE for crack formation leaks. Risk values obtained were compared with an acceptance level value in order to determine if the risk should be neglected or not. Weights for causes were determined by multiplying their weighting value with the risk. Risk analysis helped identify and manage risk and decision making helped to understand these risks, took appropriate actions and minimized impact in the case of disasters [11].

A model capable of receiving continuous data, can be processed with environmental and human factors and translated into real time risk awareness and insight. A real-time representation of current and cumulative risk could aid decision makers with critical information and insight. An example using a surface graph to represent the storage tank condition over a ten-week period showed the steady reduction in the score associated with "lack of operating procedures". Research is now moving on to consider Multicriteria Decision Making Systems [12-15] 


\section{References}

1. Daqing, W., Peng, Z., Liqiong, C. Fuzzy fault tree analysis for fire and explosion of crude oil tanks "Journal of Loss Prevention in the Process Industries" 26, 1390-1398 (2013).

2. Marhavilas, P.K., Koulouriotis, D., Gemeni, V. Risk analysis and assessment methodologies in the work sites: On a review, classification and comparative study of the scientific literature of the period 2000-2009. Journal of Loss Prevention in the Process Industries 1924, 477-523 (2011).

3. José, L., Carmen, G-C., Cristina, G-G., Piedad, B. Risk Analysis of a Fuel Storage Terminal Using HAZOP and FTA "International Journal of Environmental research and public health" 14, 705 (2017)

4. Juran, J.M. Juran's Quality Handbook McGraw-Hill. 5, (1999)

5. Watson, G. The Legacy Of Ishikawa. Quality Progress. 37(4), 54-47 (2004).

6. Ciocoiu, C. N. Managementul riscului. Teorii, practici, metodologii. Bucharest: ASE. (2008)

7. Institute of Ergonomics \& Human Factors. Institute of Ergonomics \& Human Factors. http://www.ergonomics.org.uk/ accessed $15 / 6 / 2018$

8. Ilie, G. De la management la guvernare prin risc. Bucharest: UTI Press \& Detectiv (2009).

9. James C., Cheng-Chung, L. A study of storage tank accidents Journal of Loss Prevention in the Process Industries 19(1), 51-59 (2006).

10. Ilie, G., Carmen, N.C. Application of Fishbone diagram to determine the risk of an event with multiple causes "Management Research and Practice" 2(1), 1-22 (2010).

11. Ikwan, .F. Reducing energy losses and alleviating risk in petroleum engineering using decision making and alarm systems "Journal of computing in systems and engineering" 422-429 (2018).

12. Haddad, M., Sanders, D., Gegov, A., Hassan Sayed, M., Huang, Y., Al-Mosawi, M. Combining multiple criteria decision making with vector manipulation to decide on the direction for a powered wheelchair. Intelligent Systems and Applications, Advances in Intelligent Systems and Computing; vol. 1037. Springer, 680-693 (2019).

13. Haddad, M., Sanders, D., Bausch, N. Selecting a robust decision making method to evaluate employee performance. International Journal of Management and Decision Making. 18, 4, 333-351 (2019).

14. Haddad, M., Sanders, D., Tewkesbury G. Selecting a discrete Multiple Criteria Decision Making method to decide on a corporate relocation. Archives of Business Research. 7, 5, 48-67 (2019).

15. Haddad, M., Sanders, D. Selecting a best compromise direction for a powered wheelchair using PROMETHEE. IEEE Transactions on Neural Systems and Rehabilitation Engineering. 27, 2, p. 228-235 (2019). 